\title{
Radiation Exposure during Varicocele Embolization: Does Access Site and Treated Side Matter?
}

\begin{abstract}
Purpose: The purpose of the study was to evaluate radiation exposure during varicocele embolization and correlate it with access site, embolized side, and complexity of varicoceles. Materials and Methods: This retrospective study included 39 adults who underwent varicocele embolization with a combination of coils and sclerosing agents between January 2015 and December 2018. Left-sided embolization was done in 26 patients and bilateral embolization in 13 patients. Jugular access was used in ten patients, whereas upper limb access was done in 29 patients. Dose area product (DAP) and total fluoroscopy time were collected and correlated to the treated side, access site, and complexity of varicoceles. Results: The mean fluoroscopy time for left varicocele embolization was $26.76 \mathrm{~min}$, which was not statistically different $(P=0.16)$ compared to bilateral embolization (33.2 min). There was no statistical difference $(P=0.37)$ between the mean DAP for left embolization of $106,239 \mathrm{mGy} . \mathrm{cm}^{2}$ compared to bilateral DAP of $107,153 \mathrm{mGy} . \mathrm{cm}^{2}$. There was no difference in the mean DAP or fluoroscopy time between jugular vein access (DAP $=87,569 \mathrm{mGy}$. $\mathrm{cm}^{2}$, time $\left.=34 \mathrm{~min}\right)$ and upper limb venous access $\left(\mathrm{DAP}=113,086.8534 \mathrm{mGy} \cdot \mathrm{cm}^{2}\right.$, time $\left.=28 \mathrm{~min}\right)$ with $P=0.64$ and $P=0.14$, respectively. There was no statistically significant correlation between the left varicocele Bähren classification and the fluoroscopy time $(P=0.52)$ or DAP $(P=0.76)$. Conclusion: This study finds no significant difference in DAP or fluoroscopy time between jugular and upper limb venous access or between left and bilateral embolization.
\end{abstract}

Keywords: Dose area product, fluoroscopy time, radiation dose, varicocele

\section{Introduction}

Embolization or transvenous sclerotherapy of gonadal veins is an accepted nonsurgical alternative for the management of varicoceles. While minimally invasive, it entails the use of radiation with the potential risk of cancer or gonadal radiation exposure. It is the prime responsibility of the operator to reduce the radiation exposure and time as low as reasonably possible using proper radiation protection precautions. This can be challenged by the vascular anatomy, body habitus, and complexity of the varicoceles that may result in significant variations in the procedural time. The use of different embolic agents may also influence the radiation exposure and fluoroscopy time. This study aims to evaluate radiation exposure and fluoroscopy time during varicocele embolization and correlate it with access site and embolized side and the complexity of varicoceles.

This is an open access journal, and articles are distributed under the terms of the Creative Commons Attribution-NonCommercial-ShareAlike 4.0 License, which allows others to remix, tweak, and build upon the work non-commercially, as long as appropriate credit is given and the new creations are licensed under the identical terms.

For reprints contact: WKHLRPMedknow_reprints@wolterskluwer.com

\section{Materials and Methods}

This retrospective study was approved by the institutional review board, and informed consent from patients was waived. This observational study aims to examine the radiation doses during varicocele embolization and attempt to assess the risk factors associated with increased radiation exposure. The study included 39 patients who underwent varicocele embolization between January 2015 and December 2018. Data were retrieved from the radiology information system and the hospital electronic medical records. Radiation doses and fluoroscopy times were retrieved from the radiation report associated with each study. The mean age of the patients was $39 \pm 12$ years with a range of 22-68 years. Embolization was done in all cases using a combination of coils/plugs and sclerosing agents in the form of sandwich technique. Procedures were done by several operators with variable degrees of expertise from supervised trainees to consultant level as a solo operator. The exact participation

How to cite this article: Alqubaisi A, Alsaadi AS, Bashir O, Arabi M. Radiation exposure during varicocele embolization: Does access site and treated side matter? Arab J Intervent Radiol 2020;4:83-6.

\section{Abdulaziz Alqubaisi', Ali S Alsaadi ${ }^{2}$, Omar Bashir $^{3}$, Mohammad $\mathrm{Arabi}^{3}$}

\author{
${ }^{1}$ Department of Medical \\ Imaging, King Abdulaziz \\ Medical City, Riyadh, \\ Saudi Arabia, ${ }^{2}$ Department of \\ Medical Imaging, Maternity \\ and Children Hospital, \\ Ministry of Health, AlMedinah \\ Almonawarah, Saudi Arabia, \\ ${ }^{3}$ Department of Medical \\ Imaging, Division of Vascular \\ and Interventional Radiology, \\ King Abdulaziz Medical City, \\ Riyadh, Saudi Arabia
}

Received: 25-04-2020 Revised: 21-05-2020 Accepted: 17-06-2020 Online Published: 10-08-2020

Address for correspondence: Dr. Abdulaziz Alqubaisi, Department of Medical Imaging, King Abdulaziz Medical City, National Guard Health Affairs, Riyadh 13212, Saudi Arabia. E-mail: abdulazizkq@hotmail. com

Access this article online

Website: www.arabjir.com

DOI: 10.4103/AJIR.AJIR_14_20

Quick Response Code:

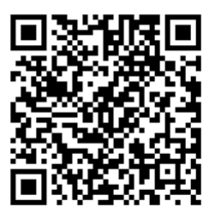


of each operator could not be determined from these retrospective data. All procedures were performed on Philips angiography machine (Allura Xper, Philips Medical Systems, Amesterdam, The Netherlands). Bilateral embolization was done in 13 patients, whereas only the left side was embolized in 26 patients. Jugular vein access was used in ten patients, whereas upper limb venous access was used in 29 patients. The choice of access was at the discretion of the primary operator. Angiographic Bähren classification of left varicoceles ${ }^{[1]}$ was retrospectively assessed in 29 patients and was correlated with radiation exposure parameters. Dose area product (DAP) and total fluoroscopy time were collected and correlated to the treated side and venous access site. Statistical analysis was done (StatPlus: Mac, AnalystSoft Inc., Version v6) using Wilcoxon and Kruskal-Wallis tests, two-sample $t$-test, and one-way analysis of variance (ANOVA).

\section{Results}

The mean fluoroscopy time for left varicocele embolization was $26.76 \mathrm{~min}$ (8.23-49.6 min), which was not statistically different $(P=0.16)$ compared to bilateral embolization mean fluoroscopy time of $33.2 \mathrm{~min}(10.3-58.83 \mathrm{~min})$ [Figure 1]. There was no statistically significant difference $(P=0.37)$ between the mean DAP for left varicocele embolization of 106,239 mGy.cm ${ }^{2} \quad(12,672-590,429)$ compared to bilateral DAP of 107,153 mGy.cm ${ }^{2} \quad(29,593-257,259)$ [Figure 2]. There was no difference in DAP or fluoroscopy time between jugular vein access and upper limb venous access $(P=0.64$ and $P=0.14$, respectively) [Figures 3, 4 and Table 1]. Using one-way ANOVA, there was no significant correlation between the left varicocele Bähren classification and the fluoroscopy time $(P=0.52)$ or DAP $(P=0.76)$ [Table 2].

\section{Discussion}

Reduction of radiation exposure during interventional procedures, particularly varicocele embolization, is paramount to minimize the radiation risks in this fertile age group. Several factors may contribute to increased radiation exposure during the varicocele embolization procedure. These can be operator or patient related. It is the prime responsibility of operators to properly adhere to standard radiation protection precautions such as tight beam collimation, lower fluoroscopy pulse rate, source-detector distance, last image hold, and most importantly reducing the fluoroscopy time. Patient-related factors include laterality of procedure, access choice, challenging anatomy, complexity of varicoceles, and the choice of embolic agent. Previous reports indicate that kerma area product rates could vary between 5.6 and $50.8 \mathrm{~Gy} . \mathrm{cm}^{2} .^{[2-4]}$ Proper utilization of meticulous radiation protection techniques such as virtual collimation and patient-positioning techniques may significantly mitigate the radiation doses to as low as 0.54 Gy. $\mathrm{cm}^{2}{ }^{[5]}$ Chalmers et al. reported $0.1 \%$ estimated

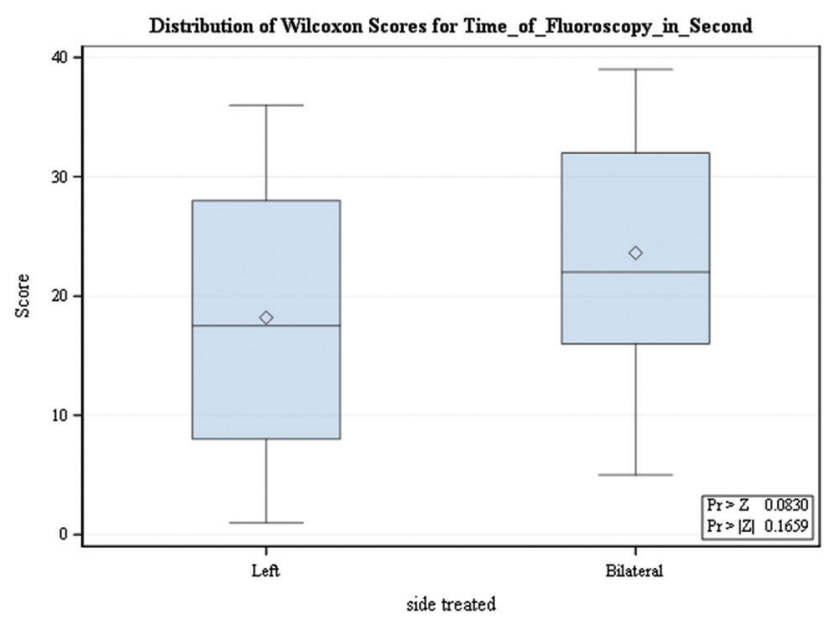

Figure 1: Correlation between the treated side and the fluoroscopy time

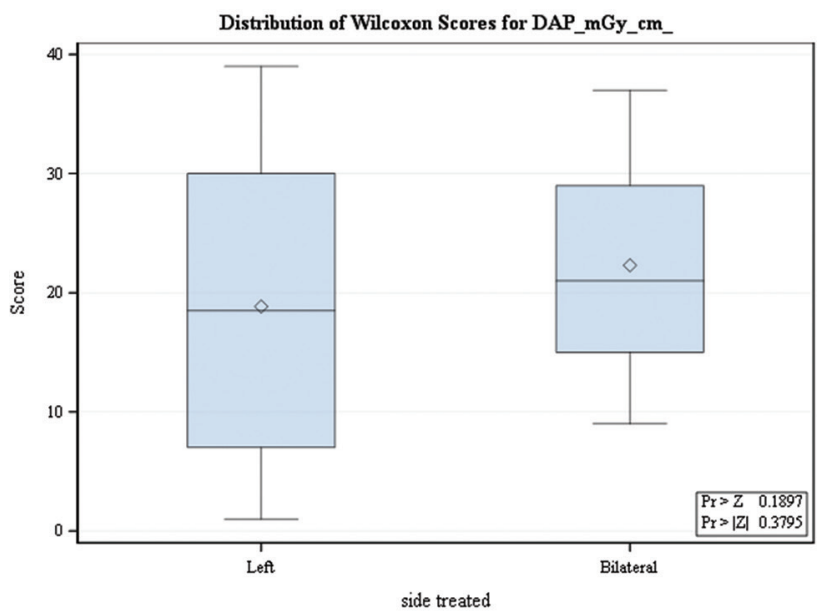

Figure 2: Correlation between the treated side and the dose area product

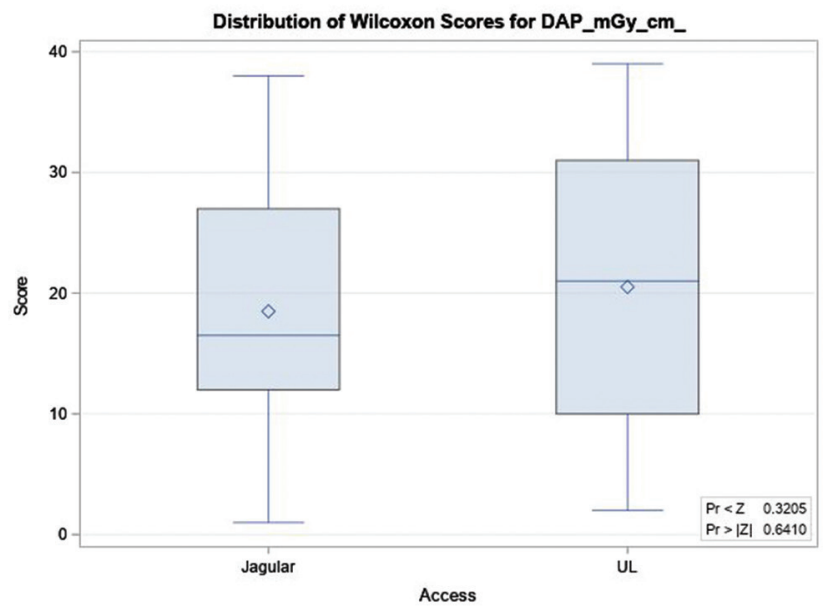

Figure 3: Correlation between the access site and the dose area product

lifetime fatal cancer risk from a retrospective study of 41 patients and showed a possible seven-fold reduction in radiation dose during varicocele embolization when using 


\begin{tabular}{|c|c|c|c|c|c|}
\hline & Patients & DAP (mGy.cm²) & $P$ & Time of fluoroscopy (min) & $P$ \\
\hline Treated side & & & 0.37 & & 0.16 \\
\hline Left & 26 & $106,239(12,672-590,429)$ & & $26.76(8.23-49.6)$ & \\
\hline Bilateral & 13 & $107,153(29,593-257,259)$ & & $33.2(10.3-58.83)$ & \\
\hline \multicolumn{6}{|l|}{ Access site } \\
\hline Jugular & 10 & $87,569(12,672-292,608)$ & & $34(8.3-49.6)$ & \\
\hline Upper limb & 29 & $113,086(12,681-590,429)$ & 0.64 & $27.6(8.23-58.83)$ & 0.14 \\
\hline
\end{tabular}

DAP: Dose area product

\begin{tabular}{lccc}
\hline \multicolumn{4}{c}{ Table 2: Correlation between the Bähren classification with the fluoroscopy time and dose area product } \\
\hline Bähren classification & Number of patients & Mean DAP (mGy.cm $)^{2}$ & Mean fluoroscopy time (s) \\
\hline 1 & 10 & $142,468(15,522-590,429)$ & $1896(1057-2825)$ \\
2 & 2 & $75,507(26,133-124,881)$ & $1730(791-2670)$ \\
3 & 7 & $84,191(16,709-235,284)$ & $1682(619-3530)$ \\
4 & 8 & $73,106(12,672-257,258)$ & $1452(494-3146)$ \\
5 & 2 & $118,420(66,223-170,617)$ & $2745(1970-3521)$ \\
Total & 29 & $102,991(12,672-590,429)$ & $1769(494-3530)$ \\
Variation between groups & & $P=0.76$ & $P=0.52$ \\
\hline
\end{tabular}

DAP: Dose area product

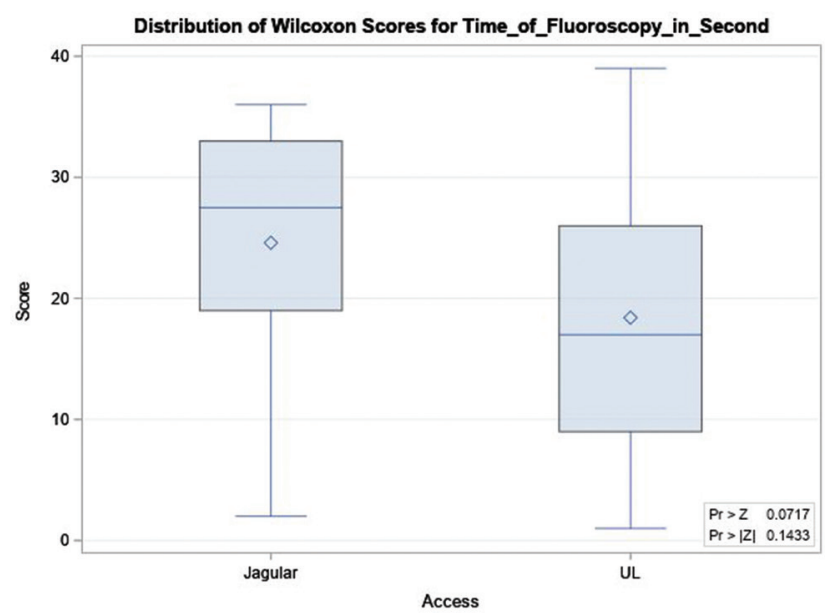

Figure 4: Correlation between the access site and the fluoroscopy time

strict radiation techniques. A study of 67 patients showed that the mean effective dose of varicocele embolization is $18 \mathrm{mSv}$ compared to $1.3 \mathrm{mSv}$ for abdominal X-ray or $4.6 \mathrm{mSv}$ for urography. ${ }^{[6]}$ In a series of 21 patients, the mean gonadal effective dose was very low $(2.15 \mathrm{mSv})$ and much lower than the threshold for the deterministic effect of temporary sterility $(150 \mathrm{mSv})$. The mean hereditary risk was $0.002 \%$, and the mean fatal cancer risk was $0.03 \%{ }^{[7]}$ Another study of 206 patients who underwent transfemoral varicocele embolization with a combination of coils and sclerosing agents showed that the maximum effective dose and maximum gonadal dose equivalent were $6.9 \mathrm{mSv}$ and $0.69 \mathrm{mSv}$, respectively. ${ }^{[8]}$ Right, left, or bilateral embolization appears to be associated with similar fluoroscopy time and DAP in a study of 237 procedures done through transfemoral approach using coils and sclerosing agents. ${ }^{[3]}$ This is similar to the observation in our study, which showed no difference in radiation exposure in relation to the treated side. The mean fluoroscopy time in this study is longer than what was previously reported in the literature, ${ }^{[2-8]}$ which can be related to several factors including the exclusive use of jugular or arm access as compared to femoral access in prior studies. This could be related to the time spent by the operators to cross from the heart into the inferior vena cava, which could have been avoided with femoral access. Furthermore, operator expertise and the level of training may have influenced the radiation exposure. In this study, there was no significant difference in DAP or fluoroscopy time between jugular and brachial/basilic veins combined. The use of coils and sclerosing agents to achieve embolization could be an additional factor leading to higher doses in the present study. The choice of embolic agent was shown to impact the radiation exposure. In a retrospective study of 182 patients, fluoroscopy time and kerma were significantly lower with glue embolization compared to mechanical embolization with coils/plugs or sclerosing agents. However, DAP was lower with glue compared to coils/plugs but not when compared to sclerosants. ${ }^{[9]}$

This study has several limitations including its retrospective nature and small sample size, which did not include any pediatric patients. The lack of data on body mass index and body habitus limits the ability to properly calculate the effective and gonadal doses. The angiographic classification of varicoceles was not available in all patients due to the lack of saved images. Operator experience and access preference may have significantly influenced the findings of this study. Furthermore, right gonadal vein cannulation may have been attempted but not documented by images or in the reports. This may have spuriously increased 
the radiation exposure and time for the left-sided cases as compared to bilateral. No femoral access was used in the study, therefore, the effect of choosing femoral access versus jugular or upper limb access in reducing the procedure time or amount of radiation cannot be evaluated.

\section{Conclusion}

This study finds no significant difference in DAP or fluoroscopy time between jugular and upper limb venous access or between left and bilateral embolization using a combination of coils and sclerosing agents. Despite its limitations, this study prompted the implementation of more cautious radiation protection measures to further minimize radiation exposure during these procedures in our institution.

Financial support and sponsorship

Nil.

\section{Conflicts of interest}

There are no conflicts of interest.

\section{References}

1. Bähren W, Biehl C, Danz B. Failed sclerotherapy trials with the V. spermatica interna. A retrospective analysis in 1141 patients with idiopathic varicocele. Rofo 1992;157:355-60.
2. Chalmers N, Hufton AP, Jackson RW, Conway B. Radiation risk estimation in varicocele embolization. Br J Radiol 2000;73:293-7.

3. Flacke S, Schuster M, Kovacs A, von Falkenhausen M, Strunk HM, Haidl G, et al. Embolization of varicoceles: Pretreatment sperm motility predicts later pregnancy in partners of infertile men. Radiology 2008;248:540-9.

4. Miller DL, Balter S, Cole PE, Lu HT, Schueler BA, Geisinger M, et al. Radiation doses in interventional radiology procedures: The RAD-IR study: Part I: Overall measures of dose. J Vasc Interv Radiol 2003;14:711-27.

5. Verstandig AG, Shamieh B, Shraibman V, Raveh D. Radiation dose reduction in fluoroscopic procedures: Left varicocele embolization as a model. Eur Radiol 2015;25:1639-45.

6. Pieri S, Agresti P, Morucci M, De Medici L, Fiocca G, Calisti A, et al. Analysis of radiation doses in the percutaneous treatment of varicocele in adolescents. Radiol Med 2003;105:500-10.

7. Gioppo FM, Azzeroni R, Primolevo A, Cionfoli N, Spinazzola A, Cornalba G. Analysis of radiation dose in varicocele embolization using a last generation $\mathrm{C}$-arm: Which risk for hereditary line? EPOS 2014. Pii: CR 2014/C-2178.

8. Gazzera C, Rampado O, Savio L, Di Bisceglie C, Manieri C, Gandini G. Radiological treatment of male varicocele: Technical, clinical, seminal and dosimetric aspects. Radiol Med 2006;111:449-58.

9. Favard N, Moulin M, Fauque P, Bertaut A, Favelier S, Estivalet L, et al. Comparison of three different embolic materials for varicocele embolization: Retrospective study of tolerance, radiation and recurrence rate. Quant Imaging Med Surg 2015;5:806-14. 